\title{
Emotional Responses to a Sexual Assault Threat: A Qualitative Analysis Among Women With Histories of Sexual Victimization
}

Kristin E. Silver

RaeAnn E. Anderson

University of North Dakota, raeann.anderson@UND.edu

Amanda M. Brouwer

\section{How does access to this work benefit you? Let us know!}

Follow this and additional works at: https://commons.und.edu/psych-fac

Part of the Psychology Commons

\section{Recommended Citation}

Kristin E. Silver, RaeAnn E. Anderson, and Amanda M. Brouwer. "Emotional Responses to a Sexual Assault Threat: A Qualitative Analysis Among Women With Histories of Sexual Victimization" (2020). Psychology Faculty Publications. 30.

https://commons.und.edu/psych-fac/30

This Article is brought to you for free and open access by the Department of Psychology at UND Scholarly Commons. It has been accepted for inclusion in Psychology Faculty Publications by an authorized administrator of UND Scholarly Commons. For more information, please contact und.commons@library.und.edu. 
Emotional Responses to a Sexual Assault Threat:

A Qualitative Analysis Among Women with Histories of Sexual Victimization

\author{
Kristin E. Silver ${ }^{1}$, RaeAnn E. Anderson ${ }^{2,3}$, \& Amanda M. Brouwer ${ }^{4}$
}

1. University of Akron, Akron, $\mathrm{OH}$

2. University of Wisconsin-Milwaukee, Milwaukee, WI

3. University of North Dakota, Grand Forks, ND

4. Winona State University, Winona, $\mathrm{MN}$

Acknowledgements: We would like to acknowledge the women who generously took the time to complete the study, along with the research assistants who helped with the coding: Samantha Lee, Rebecca Jordan, Max Gonzalez, and Jacob Wald. We would also like to acknowledge Shawn Cahill.

Correspondence may be addressed to RaeAnn E. Anderson via email at raeann.anderson@und.edu. 


\begin{abstract}
Sexual assaults against women are a leading threat to human rights and public health in the United States. Considering the high rates of sexual revictimization among women and the limited understanding of the mechanisms which fuel this phenomenon, the goal of the present study was to investigate the role of emotion in coping with a hypothetical threat of sexual assault for previously sexually victimized college women. One hundred fourteen college women with a history of sexual victimization listened to an audio-recording describing a sexual assault scenario and then described how they felt. A qualitative analysis paradigm was used to capture participants' responses in an open-ended, real-time, experiential manner. Data were analyzed using Consensual Qualitative Research - Modified methodology. Four main themes emerged (Negative Reactions, Indifferent Evaluations, Active Responses, and Cognitive Appraisal of the Situation), along with various sub-categories, demonstrating the variability of women's responses to a sexual assault threat. Many women experienced uncomfortable or distressing emotional reactions to the vignette, primarily through discomfort, but also through anger, anxiety, and being upset. Few women reported experiencing fear, and a small number reported experiencing self-blame. The low endorsement of fear and anger in our high-risk sample indicates emotional dysregulation as a potential mechanism of repeated sexual victimization and a promising target for clinical intervention. Overall, results may inform sexual assault risk reduction efforts and the empowerment of women who have experienced sexual victimization.
\end{abstract}

Keywords: sexual victimization, emotions, risk perception, sexual assault, sexual revictimization 
Emotional Responses to a Sexual Assault Threat:

A Qualitative Analysis among Women with Histories of Sexual Victimization

Many American women experience sexual victimization, representing a prevalent human rights violation and public health concern. It is estimated that perhaps up to one in four American women experiences sexual victimization in her lifetime (Fedina, Holmes, \& Backes, 2018; Muehlenhard, Peterson, Humphreys, \& Jozkowski, 2017). Sexual revictimization is when someone who was previously victimized (e.g., through childhood sexual abuse or being raped as a young adult) experiences subsequent sexual victimization. There are high rates of sexual revictimization among those with previous sexual victimization (Lalor \& McElvaney, 2010), compounding adverse health effects (Kimerling et al., 2007). Yet scientists have a limited understanding of the mechanisms which fuel this phenomenon. Overall, sexual victimization has tremendous costs to the victims, their families, and society, with consequences including depression, anxiety, post-traumatic stress, suicidality, sexual dysfunction, physical injury, sexually transmitted infections, and difficulties achieving employment and relational goals (e.g., Kelly \& Gidycz, 2018; Tjaden \& Thoennes, 2000; Yehuda, Lehrner, \& Rosenbaum, 2015).

The goal of the current study was to investigate the range of emotions elicited by sexual assault threats, using a standardized, hypothetical, threat stimulus and a qualitative analysis paradigm in a high-risk sample: women with a history of sexual victimization. We chose to focus on an open-ended qualitative analysis paradigm given prior research showing the great variety of emotions elicited by a sexual assault threat (Ambrose \& Gross, 2016), the importance of specific emotions such as anger, the difficulty women with a history of repeated sexual victimization have in emotion recognition (Melkonian, Ham, Bridges, \& Fugitt, 2017), and their experiences of emotions as barriers to defensive resistance (Macy, Nurius, \& Norris, 2006). Although 
literature exists on the emotional differences between sexually victimized and non-victimized women (Kaysen, Morris, Rizvi, \& Resick, 2005; Norris, Nurius, \& Dimeff, 1996; Stoner et al., 2007), less is known about the range of emotional responses of women who have been repeatedly sexually victimized. Therefore, we chose to incorporate a standardized stimulus because previous research has demonstrated that threat stimulus characteristics (e.g., relationship to perpetrator, severity of attack) can impact emotional reactions (Macy et al., 2006).

Considering the harm from sexual victimization, researchers have aimed to develop theories and interventions to understand and reduce the risk of sexual assaults and their sequelae. Risk perception abilities have been highlighted as a core component in potential victims' capacities to detect danger and respond effectively. The cognitive-ecological model of women's responses to male sexual perpetration (i.e., an aggressor's attempts to sexually victimize), developed by Nurius and Norris (1996), provides a framework for understanding how women perceive and respond to the risk of sexual perpetration. Nurius and Norris (1996) highlight emotion as an important part of this process, affecting risk perception and risk response.

Emotions can be considered a form of adaptive information-processing that can facilitate safety and well-being (Greenberg, 2015). Emotions consist of physiological arousal (e.g., sweating palms, racing heart), expressive behaviors (e.g., crying, clenching fists), and conscious experience (e.g., feeling sad or afraid; Myers, 2014). Different theories exist as to how these aforementioned pieces fit, but as theories of emotion have evolved, increasing emphasis has been put on the ability to apply a cognitive label to the experience and consciously appraise the situation to respond effectively (Lazarus, 1991; Schachter \& Singer, 1962).

Despite the explicit role of emotion in the cognitive-ecological model, other models for understanding sexual victimization (e.g., the Read-React-Respond model; Noll \& Grych, 2011), 
and basic research on emotion, few researchers have examined the relationship between emotion recognition and sexual assault risk perception. This has been investigated further in the child maltreatment literature, where the developmental psychopathology model arose (Cicchetti \& Toth, 2009). However, differences in information processing, and especially information processing as affected by emotional difficulties, are associated with deficits in sexual assault risk detection (Brown, Messman-Moore, Miller, \& Stasser, 2005; Wilson, Calhoun \& Bernat, 1999).

The experience of trauma, such as sexual victimization, can disrupt the natural development of emotion identification and communication skills; indeed, chronic emotion dysregulation has been hypothesized as an intervening variable for repeated sexual victimization, consistent with several theoretical models including developmental psychopathology (MessmanMoore, Ward, \& Zerubavel, 2013; Noll \& Grych, 2011; Walsh, DiLillo \& Messman-Moore, 2012). The experience of childhood sexual abuse disrupts typical emotional development. This stolen opportunity and often, the subsequent psychopathology (of many possible forms) therefore increases vulnerability to repeated sexual victimization because a person's ability to detect and respond to emotional stimuli, such as threats, is hindered. Melkonian and colleagues (2017) studied how emotion recognition impacts risk perception among people with experiences of sexual victimization. Participants who had experienced sexual victimization were less accurate in correctly recognizing facial emotions and perceived the least risk in a vignette portraying sexual assault, in comparison to non-victimized participants. This is consistent with Risser et al.'s (2006) findings that posttraumatic stress symptoms mediated the relationships between childhood sexual abuse and adult sexual victimization. Other research points to maladaptive coping with substances as an emotion regulation strategy that increases the risk of victimization via decreasing the use of protective behaviors (Messman-Moore et al., 2015; Gilmore et al., 
2016). Thus, changes in emotion and deficits in emotion regulation may affect the abilities of individuals with experiences of sexual victimization to perceive and effectively respond to sexual assault threats, thereby increasing their risk of revictimization.

\section{The Role of Emotions in Risk Response}

In contrast to the limited literature on emotion recognition and risk perception, there is a developed body of literature focusing on how specific emotions may be related to specific types of risk responses. This literature can be informative in identifying how specific emotions that mobilize effective risk responses are likely also associated with accurate risk perception, as risk perception temporally precedes risk response.

Anger. Anger is considered an essential emotion for adaptive risk detection and response to sexual assault threats. Anger and its expression can enhance the potential victim's ability to obstruct the potential perpetrator, cause the perpetrator to view the victim as less vulnerable, and can embolden potential victims to assertively resist unwanted sexual advances (Jouriles, Simpson Rowe, McDonald, \& Kleinsasser, 2014; Nurius, Norris, Young, Graham \& Gaylord, 2000). A woman's overt expression of anger may influence a perpetrator to be less likely to mistakenly presume sexual interest, as misperceiving sexual intent is related to sexual assault perpetration (Abbey, McAuslan, \& Ross, 1998). Evidence suggests that direct, forceful resistance on behalf of the potential victim is the most effective response style for reducing the risk of sexual assault, in comparison to non-assertive, diplomatic, subtle, or passive response styles (Anderson \& Cahill, 2015; Ullman, 2007). Notably, Jouriles et al. (2014) observed women reacting to sexual assault threats in a virtual role-playing scenario and found that sexually victimized women were observed to be less angry and verbalized their anger less in response to unsolicited sexual advances. 
Sadness. In contrast to anger, research suggests that the emotion of sadness can impair women's abilities to respond effectively to sexual assault threats. Nurius et al. (2000) found that non-assertive behavioral responses to a sexual assault threat were predicted by increased selfconsciousness, sadness, and concern for injury. Furthermore, sadness was associated with selfblame. Macy, Nurius, and Norris (2006) found that sadness predicted less sexual assertiveness and was associated with a history of sexual victimization. In their student sample, Frijda, Kuipers, and ter Schure (1989) found that sadness, along with related emotions such as sorrow, was associated with a perception of an experience as uncontrollable, feeling helpless, wanting to connect, and crying. Evidence suggests the emotion of sadness can impede potential victims from responding effectively to sexual assault threats.

Guilt/Self-Blame. Little research has examined how guilt or self-blame may impact risk perception directly. However, feelings of guilt and self-blame are theorized to be important and likely related to poorer risk perception (Nurius \& Norris, 1996). One study suggests self-blame is predictive of less anger in response to the threat of sexual assault (Nurius et al., 2000). Research on rape myths has found that women who endorse greater rape myths have poorer risk perception (Yeater, Treat, Viken \& McFall, 2010); conspicuously, victim-blame is a core idea of many rape myths, suggesting guilt/self-blame are important to understand.

Overall, current research and theory highlight the importance of emotion to sexual assault risk detection and response. Yet, much is still unknown about the exact role of emotional reactions in protecting potential victims of sexual assault, along with which emotions may be most critically associated with accurate risk perception. Further, it is well-established that trauma can adversely impact emotional functioning (Cloitre, Miranda, Stovall-McClough, \& Han, 2005; Thompson, Hannan, \& Miron, 2014), but little research has focused on the emotional responses 
of women with sexual victimization histories in relation to their risk perception capabilities. Therefore, the goal of the current study was to qualitatively examine the emotions of repeatedly victimized college women when facing a hypothetical threat of further sexual assault.

\section{Methods}

\section{Participants}

Participants were 114 women who were mostly Caucasian (78.9\%), although some identified as African American (14.0\%), Asian or Asian American (8.0\%), Latina (4.4\%), and Native American (4.4\%); participants could choose more than one racial identity. The sample was predominantly heterosexual (87.7\%), with 7.9\% identifying as bisexual, $1.8 \%$ identifying their sexual orientation as "other," and $0.9 \%$ identifying as lesbian or gay. The average family income was in the \$60,000-79,999 range (i.e., around the median household income in the US). The mean age of participants was $23.0(\mathrm{SD}=6.1)$. Participants were recruited to complete a larger study on barriers and facilitators of self-defense behavior in the academic year 2013-2014 (AUTHORS). Approximately 500 women were screened, and 135 completed the main study. No one withdrew from the study. Only participants with a history of repeated sexual victimization who provided adequate responses to the qualitative prompts were retained for this analysis, $n=$ 114. Participants who responded yes to a history of childhood sexual abuse or adolescent/adult sexual victimization on a Psychology subject pool screening questionnaire were invited to participate in the main study. During participation sexual victimization history was confirmed using 5 items from the Childhood Trauma Questionnaire to assess childhood sexual abuse (the same five items were used in the screening questionnaire; Bernstein et al., 1994), The Revised Conflicts Tactics Scales to assess lifetime sexual victimization from intimate partners (Straus et al., 1996), and the Sexual Experiences Survey-Short Form Victimization to assess sexual 
victimization since age 14 (Koss et al., 2007). Three items from the SES (Koss \& Oros, 1982) were also used in the screening questionnaire. All of these measures have good evidence of reliability and validity (Johnson, Murphy \& Gidycz, 2017; Paivio \& Cramer, 2004; Straus et al., 1996). Any two affirmative responses on any of these three questionnaires was coded as positive for sexual revictimization history.

\section{Procedure}

The current study was a qualitative secondary analysis of a quasi-experimental study that investigated predictors and characteristics of women's responses to a sexual assault threat (Anderson et al., 2020; Anderson et al., 2018). In the original study, respondents were randomly assigned to complete either the hypothetical sexual assault threat response task or questionnaires first. All participants completed the same procedures for the threat response task. The Institutional Review Board of the second author's university approved the following procedures.

The threat stimulus. The hypothetical threat was presented via audio recording and portrayed a stereotypical, heterosexual dating scenario that begins with a man (Dan) and a woman (Jenny) talking while they return to the man's apartment after a movie. The vignette portrays mutual interaction, including kissing and pleasant conversation, but gradually escalates to sexual assault, with the female actor depicting clear boundaries and resistance to the man's unwanted sexual advances. The entire recording is approximately five minutes long. For this study, the recording was automatically paused at a point (unknown to the participant) that represented a moderate level of threat (Anderson \& Cahill, 2014). Specifically, at this point in the vignette, the man has twice violated the boundaries articulated by the woman, touching her breasts and then her buttocks with the woman saying, "Haven't you been listening? I just told you not to touch my breasts, and now you touch my butt!" The vignette was created by paid 
actors in the 1990s and has been rated as realistic by college students across time (Benbouriche, Testé, Guay \& Lavoie, 2018; Marx \& Gross, 1995). Participants were instructed to: "Listen to the situation as if you were on this date. Try to imagine how you would feel if you were Jenny. At some point, the recording will automatically end. You may choose to end the recording or pause it at any point." Once the recording ended, participants were asked, "Putting yourself in Jenny's position, how do you feel about this date right now?" A small literature of research (approximately 20 citations) has utilized this recording to identify characteristics of sexual assault threat perception and response regularly since 1995 (e.g., Benbouriche et al., 2018; Spokes, Hine, Marks, Quain, \& Lykins, 2014; Wilson et al., 1999). This recording has also been used as evidence of efficacy of a sexual assault risk reduction program (Newins \& White, 2018). Thus, the use of this recording extends an existing literature on a useful experimental analog method.

\section{Data analysis}

Qualitative data were analyzed using Consensual Qualitative Research - Modified methodology (CQR-M; Spangler, Liu \& Hill, 2012). CQR-M is an adaptation of Consensual Qualitative Research Methodology (Hill, 2012; Hill et al., 2005; Hill, Thompson \& Williams, 1997) for analyzing relatively brief, simple qualitative data for large samples. To maintain validity, CQR-M requires researchers to undergo a three-step process to analyze data (Hill et al., 2005; Hill, Thompson, \& Williams, 1997; Spangler et al., 2012). In the first step, researchers individually reviewed transcripts and derived domains and categories. Then the research team met together and came to a consensus. Disagreement on codes is common in the early part of the coding process. To resolve disagreements, each coder described the evidence and cognitive process he or she underwent to arrive at the initial code. Questions and clarifications were 
discussed among coders, and consensus was reached by some coders changing their initial codes after discussion, creating a new code, or by modifying or expanding the current definition of a theme to better represent various codes. Although coders in the current study had several disagreements, many were related to sub-categories rather than major themes. There was general agreement among most coders on the major themes developed in the study. Once all researchers agreed on categories and domains, these were then applied to all transcripts. Data are coded and re-coded as necessary, and modifications to domains and categories are made as new data are presented. This recursive process occurs until all researchers reached a consensus with each code, domain, and category. Saturation occurred when no new themes emerged, and findings were considered stable once saturation was achieved (Williams \& Hill, 2012). In the final step, researchers analyzed the response frequency by calculating the proportion of each domain, subdomain, and categories (i.e., the number in each domain/category divided by the number of participants). Coders were four undergraduate students from two universities, two women and two men. The coders were trained and supervised by the second and third authors.

\section{Results}

In response to the question, “putting yourself in Jenny's position, how do you feel about the date right now?" participants' remarks were coded into four domains: Negative Reactions, Indifferent Evaluations, Active Responses, and Cognitive Appraisal of the Situation. Table 1 presents definitions and frequencies for each domain and category. Participants' responses could contain more than one domain; thus, some of the exemplars below portray multiple domains.

Negative Reactions. Most participants (73.6\%) had negative reactions or expressed some degree of discomfort toward the progression of the date. Several sub-themes, describing specific 
negative evaluations, were identified within this domain and included discomfort, anger, anxiety, being upset, self-blame, and fear.

Discomfort. Many participants (40.4\%) described feelings of discomfort after listening to the dating scenario. Participants explicitly expressed feeling "awkward," "extremely uncomfortable," “embarrassed," and "creeped out." One participant said, "I would feel uncomfortable because I wouldn't want Dan touching my body parts that I asked not to be touched." Another participant noted, "The date was going well, but once Dan continued to touch me after I told him to stop, I began to feel uncomfortable and wanted to stop."

Anger. Participants (21.9\%) described feeling angry, noting that they were "irritated," "frustrated," "annoyed," and "aggravated." One participant reported being "angry that my date won't listen and annoyed that he won't stop touching me in places I don't want to be touched."

Anxiety. Participants (9.6\%) also expressed how the situation made them "nervous" or "anxious," with one participant saying, "I would be nervous at this state since he didn't listen the first two times." Others described how they felt concern or worry about the situation. For example, participants stated that the date was "not going well," and that they were "beginning to become concerned." One participant explained her concern as it related to Dan's behaviors, noting, 'I don't like that he's trying to excuse his behavior by saying 'you drive me crazy.' He's not taking responsibility for his behavior, and that worries me.” Another participant expressed her anxiety as a function of how she would handle the situation, "I would worry about how I would get myself out of the situation (getting a ride home, etc.) and begin to worry that since he's not listening to how I ask him to stop if he will do more unwanted things."

Being upset. These statements often identified mild distress, but the description of the emotion experienced was relatively vague. Participants $(7.0 \%)$ described their responses to the 
event as being upset or saddened by the events that transpired. One participant responded, "I am a little upset that he continued to touch her and she told him to stop.” Another said, ". . .clearly he isn't listening which would make me upset." Others described how upsetting the situation was by describing how they felt "violated" as a result of Dan's actions.

Fear. Although infrequent, some participants (2.9\%) noted feeling fear as a result of the situation. Some participants identified that they felt "scared," with one participant saying, "I would feel scared if I continued to stay. It would lead to something I didn't want."

Self-blame. A small number of participants (2.6\%) also reported a degree of self-blame when describing how they felt about the situation. Participants reasoned that the situation would have only happened because of something that Jenny (i.e., themselves) did. For example, one participant stated, “I feel like I'm sending mixed signals! I feel like I am leading him on and being a tease!" Another noted, “I feel if she wasn't feeling him on a sex level, maybe she shouldn't have went to his house or have him over [to] hers."

Indifferent Evaluations. Some participants (7.0\%) expressed a degree of indifference about the date. Their responses were neither negative nor positive, and they did not explicitly express whether the date would do harm or good for the individuals on the date. Participants described the situation as, "It's all right," "Fine, I guess," and "It seems okay."

Active Responses. In addition to participants expressing how they felt about the scenario, a small group of participants (4.4\%) described how they would directly involve themselves in the situation and for some, how they would physically intervene, fight back, or stand up for themselves. The majority of responses within this sub-code identified that the course of action participants should take is to leave or end the date. Many noted that "the date should end" or that they "would leave immediately." For example, participants said, "I would not want to stay at 
Dan's house and would probably ask to leave," and "It is not what she wants so she should get up and leave before it goes too far." Others offered alternative actions, including suggesting that Dan take it slower. For example, one participant said, "I would just tell him that I want to take things slow and maybe that I should leave or see him on our next date."

Cognitive Appraisal of the Situation and Dan (The Perpetrator). In addition to describing general emotions about the experience or situation, many participants $(24.6 \%)$ also provided an evaluation of the situation when describing their emotions about the event or did not describe their emotions at all. Some participants commented on what was currently happening, stating, "That it [the date] is not going the way she wants it to," and "I feel Jenny is being taken advantage of and she should leave before it gets worse." Others offered suggestions for what should happen, stating, "It needs to end," and "It should probably end, because he isn't going to give up." Finally, some participants described what they thought of the date and at what point the context of the date changed. For example, one participant said, "It was going good, but then the guy started to get too physical. She just wanted to kiss and cuddle, and he wanted to do more."

Many of these evaluative statements included the participants' thoughts and feelings about the perpetrator in the situation, Dan. For example, one participant stated, 'I don't think he [Dan] is the right guy for me if he can't respect my body as well as my feelings." Another participant noted, "He [Dan] is doing other things that I don't want to do at that time." Other example statements include, “Because he wasn't listening, I would feel like he didn't care about how I felt," "He cannot seem to control his urges," and "He is showing that he doesn't respect me/women, and that he's probably pushy and selfish in a lot of ways, and that sex might be the only reason he wanted to hang out with me." 
Table 1

Domains, Categories, and Frequencies of Participants' Responses $(N=114)$

\begin{tabular}{|c|c|c|}
\hline Domains and Categories & Operational Definition & $\begin{array}{l}\text { Frequency } \\
\text { (coded response) }\end{array}$ \\
\hline Negative Evaluation & An unfavorable feeling toward the date. & $84(73.6 \%)$ \\
\hline Discomfort & Feeling uncomfortable with the situation. & $46(40.4 \%)$ \\
\hline Anger & $\begin{array}{l}\text { Feeling irritated, annoyed, and angry with the } \\
\text { situation. }\end{array}$ & $25(21.9 \%)$ \\
\hline Anxiety & $\begin{array}{l}\text { Expressing a degree to worry or concern about } \\
\text { the situation. }\end{array}$ & $13(9.6 \%)$ \\
\hline Being upset & $\begin{array}{l}\text { Feeling emotional instability or unhappiness } \\
\text { with the date. }\end{array}$ & $8(7.0 \%)$ \\
\hline Fear & $\begin{array}{l}\text { Experiencing distress or being scared as a } \\
\text { result of the situation. }\end{array}$ & $4(2.9 \%)$ \\
\hline Self-blame & $\begin{array}{l}\text { Feeling that the events that transpired were the } \\
\text { responsibility and fault of the participant. }\end{array}$ & $3(2.6 \%)$ \\
\hline Indifferent Evaluations & $\begin{array}{l}\text { Emotions were apathetic without feeling that } \\
\text { harm or benefit would come from the situation. }\end{array}$ & $8(7.0 \%)$ \\
\hline Active Responses & $\begin{array}{l}\text { Directly involving oneself in the situations. } \\
\text { Offering tangible behaviors as a result of the } \\
\text { dating situation. }\end{array}$ & $5(4.4 \%)$ \\
\hline $\begin{array}{l}\text { Cognitive Processing the } \\
\text { Situation and Dan }\end{array}$ & $\begin{array}{l}\text { Expressing how one thought about the } \\
\text { situation rather than how one felt or what one } \\
\text { would do. Participants often include statements } \\
\text { about their reaction to Dan's behavior. }\end{array}$ & $28(24.6 \%)$ \\
\hline
\end{tabular}

\section{Discussion}

Emotions are automatic, biologically-based tendencies that are necessary for survival, as they allow an individual to perceive threats to safety (Greenberg, 2010, 2015; Vuilleumier et al. 
2001). Sexual assault is a significant threat to American women, and research has identified emotional processes as a critical component impacting risk perception, and subsequent risk response, to sexual assault threats (Nurius \& Norris, 1996). For the current study, a sample at high risk for sexual victimization was recruited: women who already had a history of sexual victimization. Amongst such women, the current study aimed to identify specific emotions that arise when responding to the hypothetical risk of sexual assault. Results of the present study speak to the diversity of women's responses to a sexual assault threat, as many women reported diverse negative reactions, while others described indifferent responses. Some reported taking an active behavioral response, while others cognitively appraised the situation.

Negative Reactions. That most women expressed some form of negative reaction in response to the threat broadly speaks to women's abilities to perceive some risk in the sexual perpetration scenario portrayed. Almost half of women reported feeling discomfort, a fifth reported experiencing anger, and others reported experiencing anxiety or being upset. Smaller numbers of women reported experiencing fear or self-blame. However, it is concerning that a threat was not perceived unanimously, considering the moderate level of threat portrayed in the scenario (Anderson \& Cahill, 2014), the high prevalence of sexual assault in the US (e.g., Fedina et al., 2018; Muehlenhard et al., 2017), and the sexual victimization histories of the respondents. Negative reactions, particularly anger, can facilitate an assertive response (Nurius et al., 2000). Findings in the current study lend support to the aforementioned explanatory models of sexual revictimization (e.g., developmental psychopathology, Cicchetti \& Toth, 2009; ecological model, Messman-Moore \& Long, 2003; Read-React-Respond, Noll \& Grych, 2011). These models posit that individuals who experience sexual victimization, especially from childhood, may have difficulties in emotion identification and emotion regulation, perhaps resulting from 
dysregulation of the body's stress response system, that can ultimately thwart self-protective responses to a sexual assault threat.

Anger. Anger can be an empowering emotion for people with experiences of sexual victimization, mobilizing them into action when confronted with a threat and therefore serving a protective function (e.g., Jouriles et al., 2014; Nurius et al., 2000). Anger in response to having one's rights violated reflects a sense of deservingness to respectful treatment and an entitlement to fairness. However, anger was reported by $21.9 \%$ of respondents, perhaps indicating a lack of awareness that the woman in the vignette was indeed being violated and/or that the woman deserved to be treated better. A woman who does not experience anger in response to having her bodily integrity violated may be less likely to defend herself, and if watching this situation as a bystander, to recognize when another person is at risk.

Fear. The vast majority of participants $(97.1 \%)$ did not report a fear response. As this study did not have a control group, it is not known how this response rate might differ from the population at large. However, it may be clinically relevant, considering the threatening sexual assault scenario portrayed. The response of "anxiety" reported by $9.6 \%$ of the sample is akin to a low-level of fear, yet it is likely not enough to cause an active fear response. In crises, the sympathetic division of the autonomic nervous system prepares the body for response: fight, flight, or freeze. According to the fight-flight-freeze model of response to threat, fear is assumed to be a mobilizing response, but it rarely emerged in our respondents, all of whom had sexual victimization histories (Maack, Buchanan, \& Young, 2015).

Multiple explanations may elucidate this finding. For example, one can assume that being attacked with a knife would be enough of a threatening stimulus to motivate someone to actively escape or draw attention to their plight, perhaps by running away and/or screaming for help. Yet 
perhaps this level of fear cannot be assumed to be elicited in a sexual assault threat scenario where the woman knows the potential perpetrator (e.g., a date rape scenario, which is much more common than attack by a stranger) within a culture that minimizes men's sexual violence against women (Burt, 1980). In conjunction with the emotional dysregulation that can occur following the trauma of sexual assault (Walsh et al., 2012), it may be unrealistic to expect that women with experiences of sexual victimization will uniformly respond with intense fear when in a potentially high-risk situation. Instead, learning to pay attention to their less acutely distressing but equally valid and more frequent—emotional experiences of discomfort, anxiety, and "being upset" may be more helpful in recognizing risky scenarios than relying on fear to motivate an active behavioral response to escape or fight back. Further, research suggests that for people with histories of chronic maltreatment, they may "mentally" rather than physically remove themselves from the threat, such as through dissociation, as this was their only option in their abusive childhood environment (Thompson et al., 2014).

Self-blame. To assume responsibility for the behavior of the perpetrator reflects an internalization of sexist beliefs and harmful rape myths. Women who blame themselves for "getting themselves into a bad situation," as opposed to recognizing the responsibility of the perpetrator, may be less likely to refuse sexual advances assertively and respond effectively to the sexual assault risk they identify. Self-blame could also lead to sexual compliance, which is when a person consents to, or does not resist, sexual behaviors despite not wanting to engage in the sexual behavior; this is a relatively common behavioral response to threat (Anderson et al., 2016; Katz \& Tirone, 2010). Sexual compliance is frequent among women in heterosexual relationships and is linked to sexual victimization, perhaps because women who have been sexually victimized previously may comply with unwanted sex to avoid being forced into sexual 
behavior (Impett \& Peplau, 2003). Indeed, Katz and Tirone (2010) found that a man's sexually coercive behavior toward his female partner temporally preceded her sexually compliant behavior. Even in cases without overt violence, when a woman prioritizes the desires of her sexual partner over her own wants and desires, it can create a sense of obligation to engage in unwanted sexual activity, leading to a downward spiral of further self-blame, shame, and risky sexual behavior.

Indifferent evaluations. Notably, some women in the current study responded indifferently to the sexual assault threat, indicating they did not recognize or acknowledge the risk. This may relate to a lack of knowledge and awareness regarding healthy, respectful sexual relationships with a partner that is responsive to one's needs and concerns. Additionally, this response could represent desensitization to sexually inappropriate, aggressive behavior over time, as these women had previous histories of sexual victimization. The extent and severity of their previous sexual victimization(s) may have led to less emotional reactivity to threat and/or difficulty in registering moderate threats as dangerous.

Active responses. Women who had active responses remarked that they would proactively change the course of the date to protect themselves, such as by speaking out or fighting back against Dan. Most women with responses in this category insisted either the date should end or they (Jenny) should leave. Research suggests these types of active, assertive responses that forcefully resist the perpetrator are the most effective in reducing a potential victim's risk of sexual victimization, in comparison to response styles that are more passive or indirect (e.g., Anderson \& Cahill, 2015; Ullman, 2007). In this dataset, Anderson et al. (2020) investigated the predictors of different methods of self-defense when college women with sexual victimization histories were confronted with a sexual assault threat in the lab. They found that 
women's past real-life assertive behavioral responses predicted their lab-based assertive responses, while controlling for rape acknowledgement. Further, African-American women, compared to women of other racial/ethnic backgrounds, used more assertive responses. Although $4.4 \%$ of the sample in the current study provided active responses, these response types represent an area of strength and could be a mechanism of risk reduction in their actual lives.

Cognitive appraisal. The theme of cognitive appraisal was broadly used to describe a diverse set of responses that did not specifically answer the question of "how do you feel about the date right now?" Respondents partially responded with reporting their emotions or declined to report on their emotions entirely, instead answering with their thoughts. Participants may have been intellectualizing the event or may have misread the question. Alternatively, participants who did not answer the question correctly may have conflated their thoughts and emotions due to a lack of emotional literacy and/or (unintentionally) distanced themselves from the question due to a desire for self-protection. Notably, many participants spoke about the woman in the scenario in the third person, as opposed to answering the question with how they would personally feel. These responses could be due to emotional avoidance resulting from trauma, may be an artifact of the specific population studied, and/or could result from limits to the stimulus itself (i.e., it did not elicit a substantial amount of emotion).

However, a domain with protective implications did emerge under this category. Some participants were very focused on Dan's behavior, including pointing out his lack of respect and probable selfishness. Perhaps these participants had well-developed threat response systems, such that the emotional appraisal was so automatic that they immediately responded behaviorally and/or with a critical evaluation of the perpetrator. Accordingly, this type of cognitive appraisal that focuses on the harmful behavior of the perpetrator could represent an area of intervention. 
However, responses that seem to excuse the perpetrator's behavior (e.g., "He cannot seem to control his urges") require further examination and psychoeducation to help individuals unlearn harmful rape myths that excuse violence against women and make rape seem inevitable.

\section{Clinical and Educational Implications}

Contemporary theorists view emotions as meaningful because they inform people that a pressing need, value, or goal may be met or impaired in a situation. The ability to identify, manage, and communicate emotions is essential to the development of a self-concept, effective communication, and healthy relationships. As emotions are considered involuntary (Vuilleumier et al. 2001), it is not a realistic therapeutic goal to make someone experience an emotion-or stop experiencing an emotion — in relation to a particular situation or threat. However, building a sense of entitlement to respectful treatment, including by educating individuals on the characteristics of a healthy, pleasurable, non-coercive sexual relationship, can build positive relationship expectancies for those with previous experiences of sexual victimization. Per Macy et al. (2006), women with positive relationship expectancies are more likely to experience anger when confronted with an assailant; thus, women who expect to be treated respectfully experience anger when these expectations are violated. By building a person's sense of deservingness, it may increase the likelihood that she will experience anger if violated in the future. This process speaks to the therapeutic and practical importance of getting women in touch with their anger, which can be protective and mobilizing when women are faced with disrespect or discrimination across many domains of life, not just in response to the threat of sexual assault.

Notably, to describe oneself as "upset" is a generalized, diffuse term that can minimize one's own experience. Women may use this term because it is more socially acceptable and gentler for a woman to say she is "upset" than something more specific and pointed such as 
"pissed" or "angry," considering the restrictions against women's expressions of anger in many cultures (Worell \& Remer, 2003). Differentiating global upset or distress into more discrete terms may help develop emotional identification skills that would allow a woman to explore the meaning of her feelings and learn emotion regulation skills as necessary. Empirically supported therapeutic paradigms that teach emotion recognition and regulation skills include Dialectical Behavior Therapy (Linehan, 1993) and Emotion-Focused Therapy (Greenberg, 2010, 2015).

The lack of a unanimous recognition of a sexual assault threat within this sample of women who have been previously sexually victimized may have multiple etiologies. Perhaps participants suffering from mental health diagnoses such as depression, anxiety, and/or posttraumatic stress are experiencing difficulties with emotion avoidance and/or emotion regulation that makes threat perception tasks exceedingly difficult. Further, results may speak to the low levels of sexual literacy and gender equality in US society.

The psychotherapeutic, psychoeducational work of building women's sexual entitlement and positive relationship expectancies should be incorporated into sexuality education courses through a feminist lens. The potential of comprehensive sexuality education to serve as a primary prevention strategy for sexual assault remains a promising - yet still unstudied — area of intervention (Schneider \& Hirsch, 2018). By educating people on such factors as the characteristics of a healthy relationship, sexual consent, rape myths, and the reality of sexual perpetration, individuals can become empowered to identify when sexual perpetration is occurring, respond effectively to threats to themselves and others, expect more from their sexual partners, and not tolerate disrespectful treatment.

Rape and sexual assaults occur in a cultural context of gender inequality, with women at a disadvantage, and some women may have multiple disadvantages (e.g., living in poverty) that 
raise their risk of sexual victimization and/or complicate their recovery (Worell \& Remer, 2003). Clinicians and educators should be mindful of the social locations of women coping with sexual victimization, taking care to respond sensitively to their individual and cultural differences around such variables as class, race, age, sexual orientation, immigration status, and ability.

\section{Limitations and Future Research}

Although the current study enriches our understanding of the range of emotions elicited by a hypothetical sexual assault threat, it has some methodological and sampling limitations. The hypothetical scenario of sexual assault utilized in the recording may not have elicited the fullrange or intensity of emotions that would emerge in a real sexual assault scenario. Even though participants did not specify a certain emotion, it is possible they still felt it; individuals may have had difficulty articulating their emotional experiences. Furthermore, the "date rape" scenario portrayed, though more statistically frequent, may not be as emotion-inducing and scary as a more stereotyped, though less statistically probable, sexual assault scenario (e.g., forcible rape by a stranger with a weapon). Future researchers could explore how a more emotion-inducing scenario might affect emotional responses. Additionally, how victimization in the context of an intimate relationship might elicit different emotions than victimization by a non-intimate (e.g., a stranger) could be further studied. Likewise, the current study only elicited experiences from women with a history of sexual victimization, so it is not possible to compare their responses to women without such a history. Results cannot be generalized beyond the current sample. The scenario portrayed was specific to heterosexual individuals and would likely be less salient to non-heterosexual respondents. Additionally, emotional responses may seem automatic to some people, making their experiences difficult to articulate for a research study. Participants did not have much racial/ethnic, sexual orientation, and age diversity. In terms of how this line of 
research can inform future work, researchers can combine standardized measures (e.g., facial coding, reports of alexithymia) with qualitative work to better understand emotional responses to sexual assault threats.

As emotional expression varies cross-culturally, research with larger sample sizes of participants from diverse cultural backgrounds can allow meaningful comparisons to be made. As noted by Anderson et al., (2020), conceptual models of how women respond to sexual assault threats (e.g., Nurius \& Norris, 1996) have not included a culturally-sensitive analysis of how responses may vary based on an individual's unique cultural background. Further research can elucidate how responses to sexual assault threats may vary based on the diverse backgrounds of individuals who have experienced sexual victimization. Such research may have relevance to culturally-specific risk reduction programming. Future research can also purposively sample a more diverse pool of applicants and match the dating scenario portrayed to the sexual orientation of respondents (e.g., a lesbian woman is shown a scenario depicting two women after a date).

\section{Conclusion}

Sexual assaults against women are a widespread, serious problem in the US. Prevention programming can only be done with sexual perpetrators, who are solely responsible for their behavior. Considering the high frequency of revictimization among women with histories of sexual victimization, the current study sought to investigate the emotional responses of women with experiences of sexual victimization to a vignette portraying a sexual assault scenario, in the hopes of better understanding their emotional responses in the context of a hypothetical sexual assault threat. The low endorsement of fear and anger in our high-risk sample indicates emotional dysregulation as a potential mechanism of repeated sexual victimization and a promising target for clinical intervention. We hope these findings will inform empowering 
clinical and educational interventions with women that can increase their sense of entitlement to respectful sexual behavior and ultimately reduce their risk of repeated sexual victimization.

\section{References}

Abbey, A., McAuslan, P., \& Ross, L. T. (1998). Sexual assault perpetration by college men: The role of alcohol, misperception of sexual intent, and sexual beliefs and experiences. Journal of Social \& Clinical Psychology, 17, 167-195. doi:10.1521/jscp.1998.17.2.167

Ambrose, C. E., \& Gross, A. M. (2016). Interpreting sexual dating encounters: Social information processing differences in men and women. Journal of Family Violence, 31, 361-370. https://doi.org/10.1007/s10896-015-9757-z https://doi.org/10.1111/j.1471-6402.2005.00237.x

Anderson, R. E. \& Cahill, S. P. (2014) Use of the response-latency paradigm for evaluating women's responses to threat. Violence \& Victims, 29(2), 248-261. doi: 10.1891/0886-6708.

Anderson, R. E. \& Cahill, S. P. (2015) Behavioral response to threat as a key behavior in sexual assault risk reduction intervention: A critical review. Aggression \& Violent Behavior, 25B, 304-313. doi: 10.1016/j.avb.2015.09.015

Anderson, R. E. Brouwer, A. M., Wendorf, A. R., \& Cahill, S. P. (2016) Women's responses to the threat of a hypothetical date rape stimulus: Exploring qualitative themes. Archives of Sexual Behavior, 45(4), 793-805. doi: 10.1007/s10508-015-0682-2 
Anderson, R. E., Cahill, S. P., \& Delahanty, D. L. (2018) Differences in the type and sequence order of self-defense behaviors during a high-risk victimization scenario: Impact of prior sexual victimization. Psychology of Violence, 8(3) 339-348. doi: 10.1037/vio0000169

Anderson, R. E., Cahill, S. P., Silver, K. E., \& Delahanty, D. L. (2020) Predictors of assertive and nonassertive styles of self-defense behavior during a laboratory-based scenario.

Violence Against Women. https://doi.org/10.1177/1077801219828542

Benbouriche, M., Testé, B., Guay, J.-P., \& Lavoie, M. E. (2018). The Role of Rape-Supportive Attitudes, Alcohol, and Sexual Arousal in Sexual (Mis)Perception: An Experimental Study. The Journal of Sex Research, 56, 766-777.

doi.org/10.1080/00224499.2018.1496221

Bernstein, D. P., Fink, L., Handelsman, L., Foote, J., Lovejoy, M., Wenzel, K., ... \& Ruggiero, J. (1994). Initial reliability and validity of a new retrospective measure of child abuse and neglect. The American Journal of Psychiatry, 151, 1132-6. doi:10.1176/ajp.151.8.1132

Brown, A. L., Messman-Moore, T. L., Miller, A. G., \& Stasser, G. (2005). Sexual victimization in relation to perceptions of risk: Mediation, generalization, and temporal stability. Personality \& Social Psychology Bulletin, 31, 963-976.

doi:10.1177/0146167204274101

Burt, M. R. (1980). Cultural myths and supports for rape. Journal of Personality \& Social Psychology, 38, 217-230.

Cicchetti, D., \& Toth, S. L. (2009). The past achievements and future promises of developmental psychopathology: The coming of age of a discipline. Journal of Child Psychology \& Psychiatry and Allied Disciplines, 50, 16-25. https://doi.org/10.1111/j.14697610.2008.01979.x 
Cloitre, M., Miranda, R., Stovall-McClough, K. C., \& Han, H. (2005). Beyond PTSD: Emotion regulation and interpersonal problems as predictors of functional impairment in survivors of childhood abuse. Behavior Therapy, 36, 119-124. doi.org/10.1016/S0005-7894(05)80060-7

Fedina, L., Holmes, J. L., \& Backes, B. L. (2018). Campus sexual assault: A systematic review of prevalence research from 2000 to 2015. Trauma, Violence, \& Abuse, 19, 76-93. https://doi.org/10.1177/1524838016631129

Frijda, N. H., Kuipers, P., \& ter Schure, E. (1989). Relations among emotion, appraisal, and emotional action readiness. Journal of Personality \& Social Psychology, 57, 212-228. doi:10.1037/0022-3514.57.2.212

Gilmore, A. K., Maples-Keller, J. L., Pinsky, H. T., Shepard, M. E., Lewis, M. A., \& George, W. H. (2016). Is the Use of Protective Behavioral Strategies Associated With College Sexual Assault Victimization? A Prospective Examination. Journal of Interpersonal Violence, https://doi.org/10.1177/0886260516628808

Greenberg, L. S. (2010). Emotion-focused therapy: A clinical synthesis. Focus, 8, 32-42.

Greenberg, L. S. (2015). Emotion-focused therapy: Coaching clients to work with their feelings. Washington, DC: American Psychological Association.

Hill, C. E. (2012). Consensual qualitative research: A practical resource for investigating social science phenomena. Washington, DC: American Psychological Association.

Hill C. E., Thompson B. J., Hess S. A., Knox S., Williams, E. N., \& Ladany, N. (2005). Consensual qualitative research: An update. Journal of Counseling Psychology, 52, 196205. 
Hill, C. E., Thompson, B. J., \& Williams, E. N. (1997). A guide to conducting consensual qualitative research. The Counseling Psychologist, 24, 517-572. doi:10.1177/0011000097254001

Impett, E. A., \& Peplau, L. A. (2003). Sexual compliance: Gender, motivational, and relationship perspectives. Journal of Sex Research, 40, 87-100.

Johnson, S. M., Murphy, M. J., \& Gidycz, C. A. (2017). Reliability and validity of the Sexual Experiences Survey-short forms victimization and perpetration. Violence \& Victims, 32, 78-92. doi:10.1891/0886-6708.VV-D-15-00110

Jouriles, E. N., Simpson Rowe, L., McDonald, R., \& Kleinsasser, A. L. (2014). Women's expression of anger in response to unwanted sexual advances: Associations with sexual victimization. Psychology of Violence, 4, 170-183. http://dx.doi.org/10.1037/a0033191

Katz, J., \& Tirone, V. (2010). Going along with it: Sexually coercive partner behavior predicts dating women's compliance with unwanted sex. Violence Against Women, 16, 730-742.

Kaysen, D., Morris, M. K., Rizvi, S. L., \& Resick, P. A. (2005). Peritraumatic responses and their relationship to perceptions of threat in female crime victims. Violence Against Women, 11, 1515-1535.

Kelley, E. L., \& Gidycz, C. A. (2019). Posttraumatic stress and sexual functioning difficulties in college women with a history of sexual assault victimization. Psychology of Violence, 9 , 98-107. http://dx.doi.org/10.1037/vio0000162

Kimerling, R., Alvarez, J., Pavao, J., Kaminski, A., \& Baumrind, N. (2007). Epidemiology and consequences of women's revictimization. Women's Health Issues, 17, 101-106.

Koss, M. P., Abbey, A., Campbell, R., Cook, S., Norris, J., Testa, M., ... \& White, J. (2007). Revising the SES: A collaborative process to improve assessment of sexual aggression 
and victimization. Psychology of Women Quarterly, 31, 357-370.

https://doi.org/10.1111/j.1471-6402.2007.00385.x

Koss, M. P., \& Oros, C. J. (1982). Sexual Experiences Survey: A research instrument investigating sexual aggression and victimization. Journal of Consulting \& Clinical Psychology, 50, 455-457. http://dx.doi.org/10.1037/0022-006X.50.3.455

Lalor, K., \& McElvaney, R. (2010). Child sexual abuse, links to later sexual exploitation/high-risk sexual behavior, and prevention/treatment programs. Trauma, Violence, \& Abuse, 11, 159-177. doi:10.1177/1524838010378299

Lazarus, R. S. (1991). Progress on a cognitive-motivational-relational theory of emotion. American Psychologist, 46, 819-834. http://dx.doi.org/10.1037/0003-066X.46.8.819

Linehan, M. M. (1993). Cognitive-behavioral treatment of borderline personality disorder. https://doi.org/10.1017/CBO9781107415324.004

Maack, D. J., Buchanan, E., \& Young, J. (2015). Development and psychometric investigation of an inventory to assess fight, flight, and freeze tendencies: The fight, flight, freeze questionnaire. Cognitive Behavior Therapy, 44, 117-127. doi:10.1080/16506073.2014.972443

Macy, R. J., Nurius, P. S., \& Norris, J. (2006). Latent profiles among sexual assault survivors: Implications for defensive coping and resistance. Journal of Interpersonal Violence, 22, 543-565. doi:10.1177/0886260506298841

Marx, B. P., \& Gross, A. M. (1995). Date rape: An analysis of two contextual variables. Behavior Modification, 19, 451-463.

Melkonian, A. J., Ham, L. S., Bridges, A. J., \& Fugitt, J. L. (2017). Facial emotion identification 
and sexual assault risk detection among college student sexual assault victims and nonvictims. Journal of American College Health, 65, 466-473. doi:10.1080/07448481.2017.1341897

Messman-Moore, T. L., Ward, R. M., \& Zerubavel, N. (2013). The role of substance use and emotion dysregulation in predicting risk for incapacitated sexual revictimization in women: Results of a prospective investigation. Psychology of Addictive Behaviors, 27, 125-132. https://doi.org/10.1037/a0031073

Messman-Moore, T., Ward, R. M., Zerubavel, N., Chandley, R. B., \& Barton, S. N. (2015). Emotion dysregulation and drinking to cope as predictors and consequences of AlcoholInvolved sexual assault: Examination of Short-Term and long-term risk. Journal of Interpersonal Violence, 30, 601-621. https://doi.org/10.1177/0886260514535259

Muehlenhard, C. L., Peterson, Z. D., Humphreys, T. P., \& Jozkowski, K. N. (2017). Evaluating the one-in-five statistic: Women's risk of sexual assault while in college. The Journal of Sex Research, 54, 549-576. doi: 10.1080/00224499.2017.1295014.

Myers, D. G. (2014). Exploring psychology in modules: 9th edition. New York, NY: Worth Publishers.

Newins, A. R., \& White, S. W. (2018). A Brief Computer-Based Sexual Assault Risk Reduction Program: A Feasibility, Acceptability, and Preliminary Efficacy Pilot Study. Journal of Interpersonal Violence, 088626051879297. https://doi.org/10.1177/0886260518792974

Noll, J. G., \& Grych, J. H. (2011). Read-react-respond: An integrative model for understanding sexual revictimization. Psychology of Violence, 1, 202-215. doi:10.1037/a0023962 
Norris, J., Nurius, P. S., \& Dimeff, L. A. (1996). Through her eyes: Factors affecting women's perception of and resistance to acquaintance sexual aggression threat. Psychology of Women Quarterly, 20, 123-145. https://doi.org/10.1111/j.1471-6402.1996.tb00668.x

Nurius, P. S., \& Norris, J. (1996). A cognitive ecological model of women's response to male sexual coercion in dating. Journal of Psychology \& Human Sexuality, 8, 117-139. doi:10.1300/J056v08n01_09

Nurius, P. S., Norris, J., Young, D. S., Graham, T. L., \& Gaylord, J. (2000). Interpreting and defensively responding to threat: Examining appraisals and coping with acquaintance sexual aggression. Violence and Victims, 15, 187-208. doi: 10.1891/0886-6708.15.2.187

Paivio, S. C., \& Cramer, K. M. (2004). Factor structure and reliability of the Childhood Trauma Questionnaire in a Canadian undergraduate student sample. Child Abuse \& Neglect, 28, 889-904. doi:10.1016/j.chiabu.2004.01.011

Risser, H. J., Hetzel-Riggin, M. D., Thomsen, C. J., \& McCanne, T. R. (2006). PTSD as a mediator of sexual revictimization: The role of reexperiencing, avoidance, and arousal symptoms. Journal of Traumatic Stress, 19, 687-698.

Schachter, S., \& Singer, J. (1962). Cognitive, social, and physiological determinants of emotional state. Psychological Review, 69, 379-399. http://dx.doi.org/10.1037/h0046234

Schneider, M., \& Hirsch, J. S. (2018). Comprehensive sexuality education as a primary prevention strategy for sexual violence perpetration. Trauma, Violence, \& Abuse, https://doi.org/10.1177/1524838018772855

Spangler, P. T., Liu, J., \& Hill, C. E. (2012). Consensual qualitative research for simple qualitative data: An introduction to CQR-M (pp. 269-283). In C. E. Hill (Ed.). 
Consensual qualitative research: A resource for investigating social science phenomena. Washington, DC: American Psychological Association.

Spokes, T., Hine, D. W., Marks, A. D. G., Quain, P., \& Lykins, A. D. (2014). Arousal, working memory capacity, and sexual decision-making in men. Archives of Sexual Behavior, 43(6), 1137-1148. https://doi.org/10.1007/s10508-014-0277-3

Straus, M. A., Hamby, S. L., Boney-McCoy, S., \& Sugarman, D. B. (1996). The revised conflict tactics scales (CTS2) development and preliminary psychometric data. Journal of Family Issues, 17, 283-316. doi.org/10.1177/019251396017003001

Stoner, S. A., Norris, J., George, W. H., Davis, K. C., Masters, N. T., \& Hessler, D. M. (2007). Effects of alcohol intoxication and victimization history on women's sexual assault resistance intentions: The role of secondary cognitive appraisals. Psychology of Women Quarterly, 31, 344-356.

Tjaden, P. G., \& Thoennes, N. (2000). Full report of the prevalence, incidence, and consequences of violence against women: Findings from the National Violence Against Women Survey (pp. 1-71). Washington, DC: US Department of Justice, Office of Justice Programs, National Institute of Justice.

Thompson, K. L., Hannan, S. M., \& Miron, L. R. (2014). Fight, flight, and freeze: Threat sensitivity and emotion dysregulation in survivors of chronic childhood maltreatment. Personality \& Individual Differences, 69, 28-32. https://doi.org/10.1016/j.paid.2014.05.005

Turchik, J. A., Probst, D. R., Chau, M., Nigoff, A., \& Gidycz, C. A. (2007). Factors predicting the type of tactics used to resist sexual assault: A prospective study of college women. Journal of Consulting \& Clinical Psychology, 75, 605-614. 
https://doi.org/10.1037/0022-006X.75.4.605

Vuilleumier, P., Armony, J. L., Driver, J., \& Dolan, R. J. (2001). Effects of attention and emotion on face processing in the human brain: An event-related fMRI study. Neuron, 30, 829-841. https://doi.org/10.1016/S0896-6273(01)00328-2

Walsh, K., DiLillo, D., \& Messman-Moore, T. L. (2012). Lifetime sexual victimization and poor risk perception: Does emotion dysregulation account for the links? Journal of Interpersonal Violence, 27, 3054-3071. https://doi.org/10.1177/0886260512441081

Williams, E. N., \& Hill, C. E. (2012). Establishing trustworthiness in consensual qualitative research studies (pp. 175-186). In C. E. Hill (Ed.). Consensual qualitative research: $A$ resource for investigating social science phenomena. Washington, DC: American Psychological Association.

Wilson, A. E., Calhoun, K. S., \& Bernat, J. A. (1999). Risk recognition and trauma-related symptoms among sexually revictimized women. Journal of Consulting \& Clinical Psychology, 67, 705-710. https://doi.org/10.1037/0022-006X.67.5.705

Ullman, S. E. (2007). A 10-Year Update of "Review and Critique of Empirical Studies of Rape Avoidance." Criminal Justice \& Behavior, 34, 411-429. https://doi.org/10.1177/0093854806297117

Worell, J., \& Remer, P. (2003). Feminist perspectives in therapy: Empowering diverse women (2nd ed.). New York: Wiley.

Yeater, E. A., Treat, T. A., Viken, R. J., \& McFall, R. M. (2010). Cognitive processes underlying women's risk judgments: Associations with sexual victimization history and rape myth acceptance. Journal of Consulting \& Clinical Psychology, 78, 375-386. https://doi.org/10.1037/a0019297 
Yehuda, R., Lehrner, A., \& Rosenbaum, T. Y. (2015). PTSD and sexual dysfunction in men and women. The Journal of Sexual Medicine, 12, 1107-1119. 